Michigan Technological University

Digital Commons @ Michigan Tech

Digital Commons @ Michigan Tech

Michigan Tech Publications

$12-14-2010$

\title{
Optimization strategy for resonant mass sensor design in the presence of squeeze film damping
}

Chengzhang Li

Michigan Technological University

Michele H. Miller

Michigan Technological University, mhmiller@mtu.edu

Follow this and additional works at: https://digitalcommons.mtu.edu/michigantech-p

Part of the Mechanical Engineering Commons

\section{Recommended Citation}

Li, C., \& Miller, M. H. (2010). Optimization strategy for resonant mass sensor design in the presence of squeeze film damping. Micromachines, 1(3), 112-128. http://doi.org/10.3390/microm1010112

Retrieved from: https://digitalcommons.mtu.edu/michigantech-p/1974

Follow this and additional works at: https://digitalcommons.mtu.edu/michigantech-p

Part of the Mechanical Engineering Commons 


\title{
micromachines
}

ISSN 2072-666X

www.mdpi.com/journal/micromachines

Article

\section{Optimization Strategy for Resonant Mass Sensor Design in the Presence of Squeeze Film Damping}

\section{Chengzhang $\mathrm{Li}^{*}$ and Michele $\mathrm{H}$. Miller}

Department of Mechanical Engineering-Engineering Mechanics, Michigan Technological University, 1400 Townsend Drive, Houghton, MI, USA; E-Mail: mhmiller@mtu.edu

* Author to whom correspondence should be addressed; E-Mail: cli2@mtu.edu; Tel.: +1-906-370-2898.

Received: 27 October 2010; in revised form: 17 November 2010 / Accepted: 6 December 2010 / Published: 14 December 2010

\begin{abstract}
This paper investigates the design optimization of an electrostatically actuated microcantilever resonator that operates in air. The nonlinear effects of electrostatic actuation and air damping make the structural dynamics modeling more complex. There is a need for an efficient way to simulate the system behavior so that the design can be more readily optimized. This paper describes an efficient analytical approach for determining the optimum design for a microcantilever resonant mass sensor. One simple case is described. The sensor design is a square plate that is coated with a functional polymer and attached to the substrate with folded leg springs. The plate has a square hole in the middle to reduce the effect of squeeze film damping. With the analytical approach, the optimum hole size for maximum sensitivity is found.
\end{abstract}

Keywords: squeeze film damping; MEMS; resonant mass sensor; optimization

\section{Introduction}

An electrostatically actuated microcantilever with an appropriate coating can serve as a resonant mass sensor for detecting chemical vapors [1,2]. The ideal resonant mass sensor experiences a large change in resonant frequency in the presence of a small gas vapor concentration. Microcantilever design is made challenging by the nonlinearities (electrostatic actuation and air damping) in the system 
model. The structural dynamics, electrostatics, and air damping can all be modeled using finite elements. However, this is a time consuming approach when doing design optimization.

Air damping has a significant effect on system $Q$ and thus sensor sensitivity. To reduce the deleterious effect of air pressure, the gap between cantilever and substrate may be increased or holes may be added [3]. The addition of holes reduces the air damping forces, the mass (thus increasing the resonant frequency), the electrostatic actuation force, the capacitance (used to sense motion), and the plate area (and thus the change in mass that occurs for a given vapor concentration). A larger gap reduces air damping, actuation force and oscillation amplitudes, and capacitance. These competing effects suggest there will be an optimum combination of hole size, hole shape, and gap.

In pursuing an analytical modeling strategy, we simplified the problem in several ways. First, rather than consider a fixed-free cantilever, we considered a rigid rectangular plate supported by folded leg springs that are narrow and long. Thus, all the deformation takes place in the leg springs, and the plate does not bend. Furthermore, the leg springs experience very little damping force compared to the plate. The plate motion is constrained such that the gap between plate and substrate is uniform for the whole plate. Also, we considered a single square hole in the center of the plate.

\section{Squeeze Film Damping Analytical Model}

Using an analytical model is computationally compact with high efficiency. Previously, extensive studies on the squeeze film damping have been performed [4-7] and have focused on the viscous damping and compressible spring effect of the fluid layer confined between parallel closed plates. Finite difference [8] and finite element models [9,10] have been developed. Perforated planar microstructures have also been studied to evaluate the influence of squeeze film damping [11]. The Reynolds equation was modified to consider the leakage flow through perforations, and variable viscosity and compressibility profiles [12]. By adding a term related to the damping effect of gas flow through holes, analytical expressions for the damping pressure for hole plates with different types of shapes have been developed, based on the concept of effective damping width, which could provide a more precise evaluation of the viscous damping for certain structures [13].

We adopted the model of Darling, et al. [10] who developed force expressions for different air venting boundary conditions. There are five basic boundary conditions: all edges vented, one edge closed, two edges closed, three edges closed, and all edges closed. All five analytical expressions are based upon a Green's function solution to the linearized Reynolds equation using the appropriate boundary conditions.

One of the ways to reduce the effect of air damping (and improve resonator $\mathrm{Q}$ and thus sensor sensitivity) is to add holes to the resonator. For example, Figure 1 depicts a square plate with a hole in the middle. The plate is divided into 8 elements. There are two kinds of boundary conditions for these elements. The four side elements (which share one side with the middle hole) have opposite edges closed; the four corner elements have two adjacent edges closed. 
Figure 1. Dividing a plate into elements that can be modeled analytically.

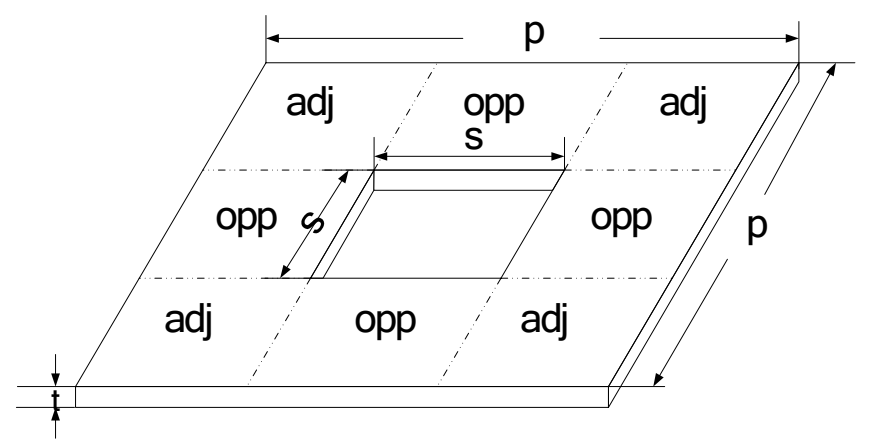

(a)

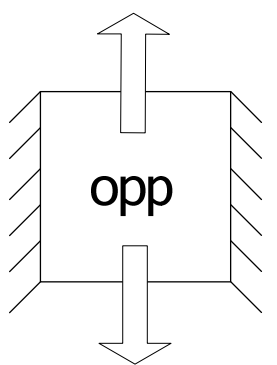

(b)

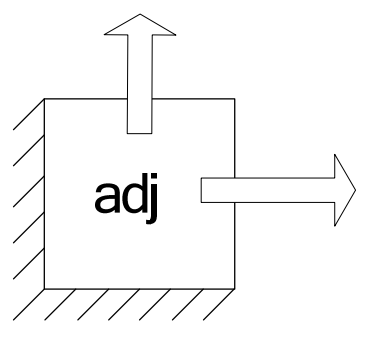

According to Darling's model [14], the spring and damping constants, respectively, for a plate with two opposite edges venting are:

$$
\begin{gathered}
k=\frac{8 \omega^{2} A P_{a}}{\pi^{2} g_{o}} \sum_{n=o d d} \frac{1}{n^{2}\left(\omega^{2}+\frac{k_{n}^{4}}{\alpha^{4}}\right)} \\
b=\frac{8 A P_{a}}{\pi^{2} \alpha^{2} g_{o}} \sum_{n=o d d} \frac{k_{n}^{2}}{n^{2}\left(\omega^{2}+\frac{k_{n}^{4}}{\alpha^{4}}\right)} \\
\alpha^{2}=\frac{12 \mu}{g_{o}^{2} P_{a}} \quad k_{n}{ }^{2}=\frac{n^{2} \pi^{2}}{b^{2}}
\end{gathered}
$$

where $\omega$ is the vibration frequency, $A$ is the plate area, $P_{\mathrm{a}}$ is the ambient pressure, $x_{\max }$ is the amplitude of vibration, $g_{\mathrm{o}}$ is the nominal gap, and $b$ is the plate dimension in the direction of venting.

For a plate with two adjacent edges venting, the spring and damping constants, respectively, are:

$$
\begin{gathered}
k=\frac{64 \omega^{2} A P_{a}}{\pi^{4} g_{o}} \sum_{m, n=o d d} \frac{1}{m^{2} n^{2}\left(\omega^{2}+\frac{k_{m n}{ }^{4}}{\alpha^{4}}\right)} \\
b=\frac{64 A P_{a}}{\pi^{4} \alpha^{2} g_{o}} \sum_{m, n=o d d} \frac{k_{m n}{ }^{2}}{m^{2} n^{2}\left(\omega^{2}+\frac{k_{m}{ }^{4}}{\alpha^{4}}\right)} \\
k_{m n}^{2}=\frac{m^{2} \pi^{2}}{4 a^{2}}+\frac{n^{2} \pi^{2}}{4 b^{2}}
\end{gathered}
$$

where $a$ and $b$ are the plate dimensions.

Let's look at the behavior of a square plate with a square hole (as in Figure 1) when modeled as a lumped system as shown in Figure 2. If the square plate has outside dimensions of $p \times p$ and hole dimensions of $s \times s$, then the corner elements with adjacent venting have dimensions $(a \times b)$ of $(p / 2-s / 2) \times(p / 2-s / 2)$, and the side elements with opposite venting have dimensions $(a \times b)$ of $s \times(p / 2-s / 2)$. 
The plate is connected to the substrate with folded leg springs having a combined stiffness of $k_{\text {flex }}$. The parameters $k_{\text {air }}$ and $b_{\text {air }}$ are found by summing the contributions of four adjacent elements and four side elements calculated from the equations above.

Figure 2. Lumped parameter model of electrostatic actuator with squeeze film damping.

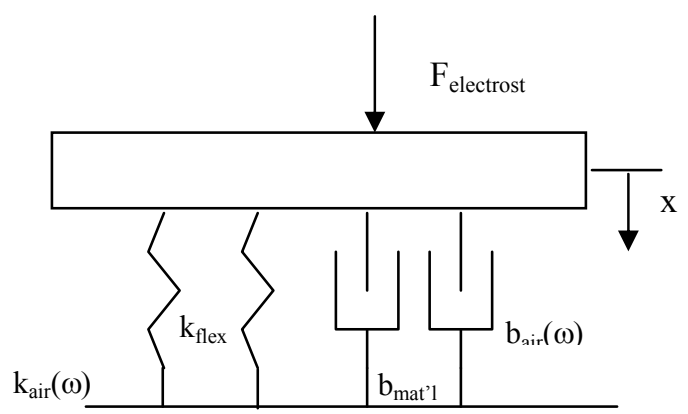

The transfer function for this system is:

$$
\begin{aligned}
\frac{X(s)}{F(s)} & =\frac{1}{m s^{2}+b s+k} \\
\text { where } m=\rho t\left(p^{2}-s^{2}\right), b & =b_{\text {matl }}+b_{\text {air }} \text {, and } k=k_{\text {flex }}+k_{\text {air }} .
\end{aligned}
$$

To get a frequency response for this system, we substitute $j \omega$ for $\mathrm{s}$ in the transfer function:

$$
\frac{X(j \omega)}{F(j \omega)}=\frac{1}{\left(k-m \omega^{2}\right)+(b \omega) j}
$$

The magnitude of this transfer function is:

$$
\left|\frac{X(j \omega)}{F(j \omega)}\right|=\frac{|1|}{\left|\left(k-m \omega^{2}\right)+(b \omega) j\right|}=\frac{1}{\sqrt{\left(k-m \omega^{2}\right)^{2}+(b \omega)^{2}}}
$$

Frequency responses were calculated using the parameters shown in Table 1.

Table 1. Parameters used to simulate air damping model for square plate with square hole.

\begin{tabular}{|l|l|}
\hline$\mu$ & $1.862 \times 10^{-5} \mathrm{~N}-\mathrm{s} / \mathrm{m}^{2}$ \\
\hline$p$ & $200 \mu \mathrm{m}$ \\
\hline$t$ & $3 \mu \mathrm{m}$ \\
\hline$g_{o}$ & $4 \mu \mathrm{m}$ \\
\hline$\rho$ & $2330 \mathrm{~kg} / \mathrm{m}^{3}$ \\
\hline$m$ & $\rho t p^{2}=2.796 \times 10^{-10}$ \\
\hline$P_{a}$ & $101,000 \mathrm{~Pa}, 3,000 \mathrm{~Pa}$ \\
\hline$s$ & $0,5,33,67,133 \mu \mathrm{m}$ \\
\hline
\end{tabular}

We looked at several different hole sizes and ambient pressures. Figure 3 shows the frequency response for different leg stiffness at atmospheric pressure $(101,000 \mathrm{~Pa})$ and with a hole size of $67 \mu \mathrm{m} \times 67 \mu \mathrm{m}$. When the stiffness increases, both the resonant frequency and Q value increase. When the stiffness is $12.9 \mathrm{~N} / \mathrm{m}$, the peak in the resonant frequency is almost flat. For lower stiffness, the 
structure would be over damped at atmospheric pressure. When the stiffness increases to $51.6 \mathrm{~N} / \mathrm{m}$, the resonant peak is sharper, and a shift in resonant peak would be fairly easy to detect. This figure shows that stiffness plays an important role in the performance of a resonant mass sensor.

Figure 4 compares the frequency responses for different hole sizes. The leg stiffness is $51.6 \mathrm{~N} / \mathrm{m}$, and the pressure of the surrounding environment is 3,000 $\mathrm{Pa}$. This figure shows the effect of a low ambient pressure: even with low leg stiffness, the Q values are better than in Figure 3.

Figure 3. Effect of leg stiffness on frequency response of square plate resonator with $67 \mu \mathrm{m} \times 67 \mu \mathrm{m}$ hole at atmospheric pressure.

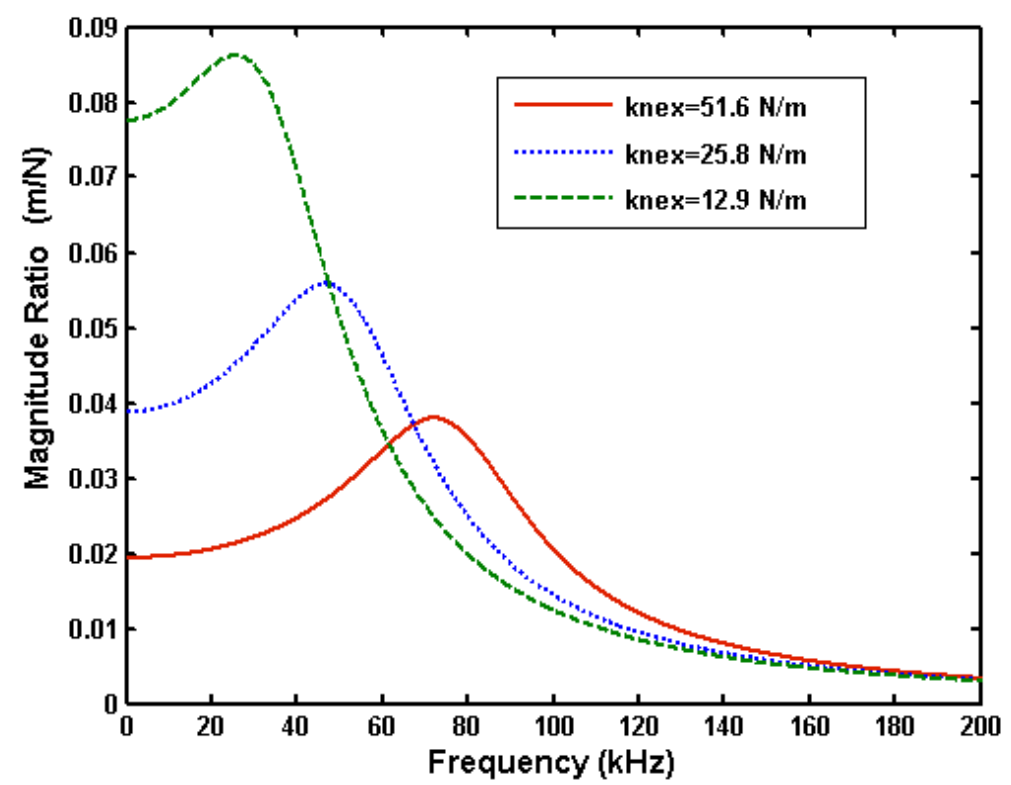

Figure 4. Effect of hole size on frequency response of square plate resonator with leg stiffness of $51.6 \mathrm{~N} / \mathrm{m}$ and 3,000 Pa ambient pressure.

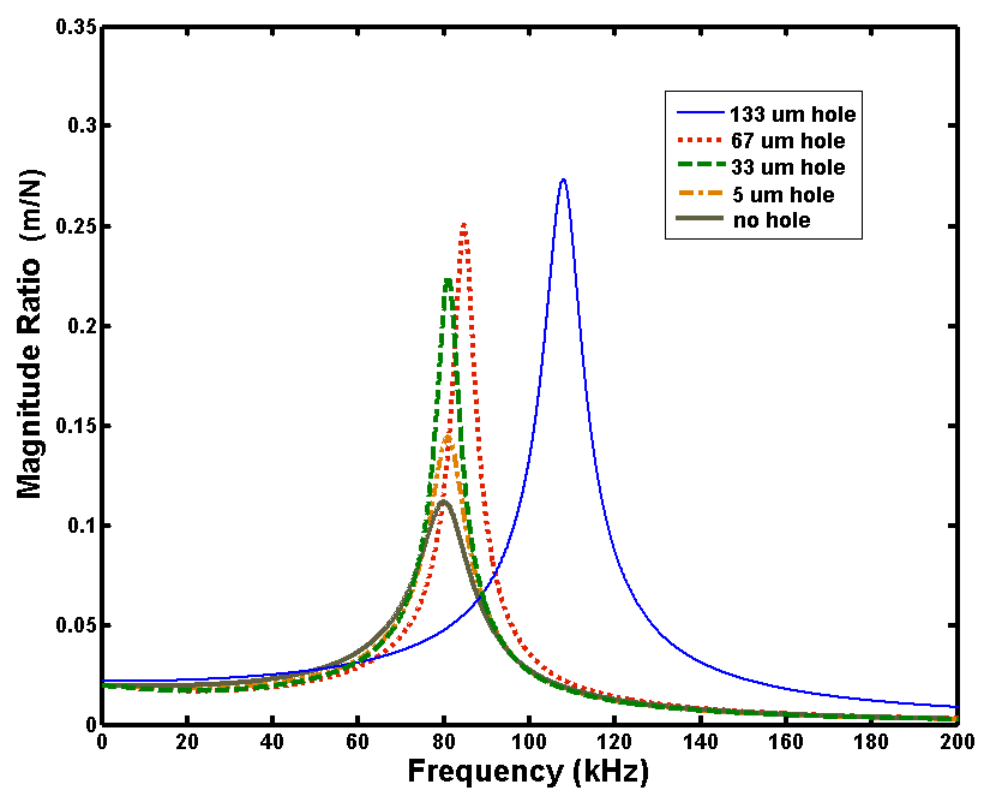




\section{Comparison with FEM Model}

We validated the analytical model using numerical finite element Comsol simulations. Figures 5-8 show the frequency responses for four sets of conditions. The conditions span different hole sizes, air pressures, and leg stiffnesses that produce a wide range of resonant frequency and damping characteristics. The figures show that the analytical model predicts the frequency responses fairly well for this wide range of hole sizes and air pressures.

Figure 5. Comparison of analytical and numerical frequency responses for square plate with $67 \mu \mathrm{m} \times 67 \mu \mathrm{m}$ hole, at atmospheric pressure, with folded leg stiffness of $51.65 \mathrm{~N} / \mathrm{m}$.

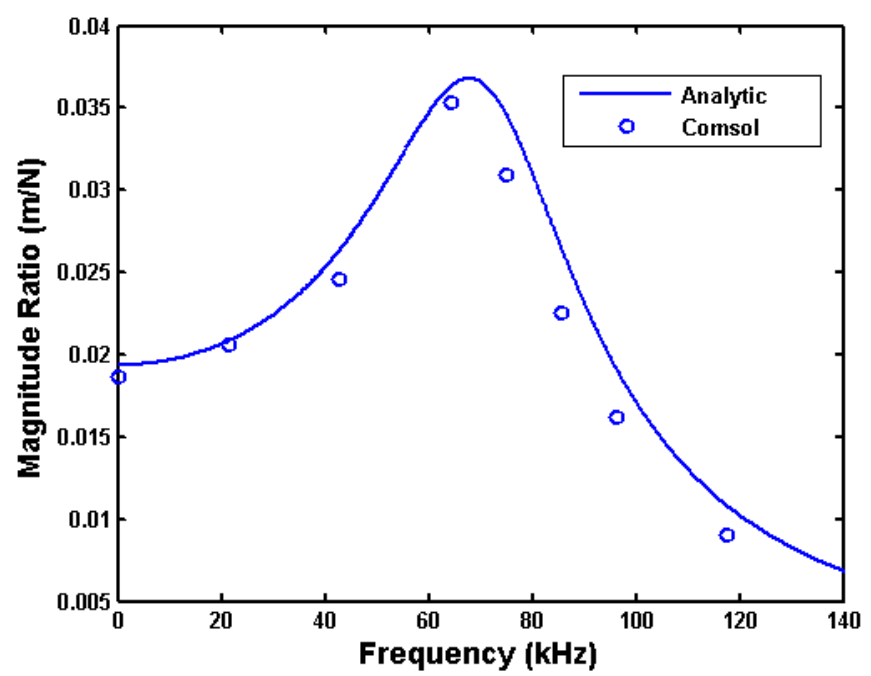

Figure 6. Comparison of analytical and numerical frequency responses for square plate with $67 \mu \mathrm{m} \times 67 \mu \mathrm{m}$ hole, at ambient pressure of $300 \mathrm{~Pa}$, with folded leg stiffness of $51.65 \mathrm{~N} / \mathrm{m}$.

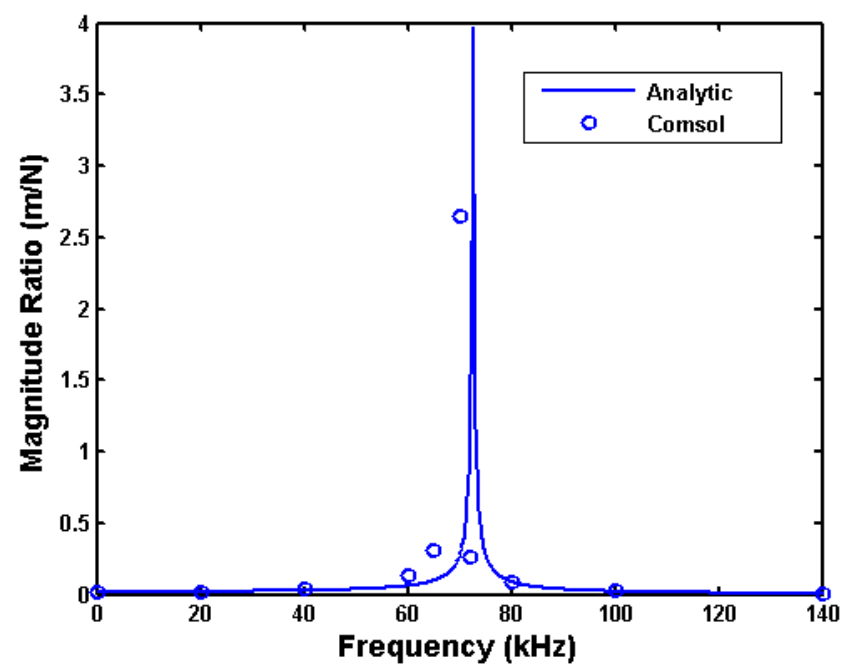


Figure 7. Comparison of analytical and numerical frequency responses for square plate with $5 \mu \mathrm{m} \times 5 \mu \mathrm{m}$ hole, at ambient pressure of $300 \mathrm{~Pa}$, with folded leg stiffness of $51.65 \mathrm{~N} / \mathrm{m}$.

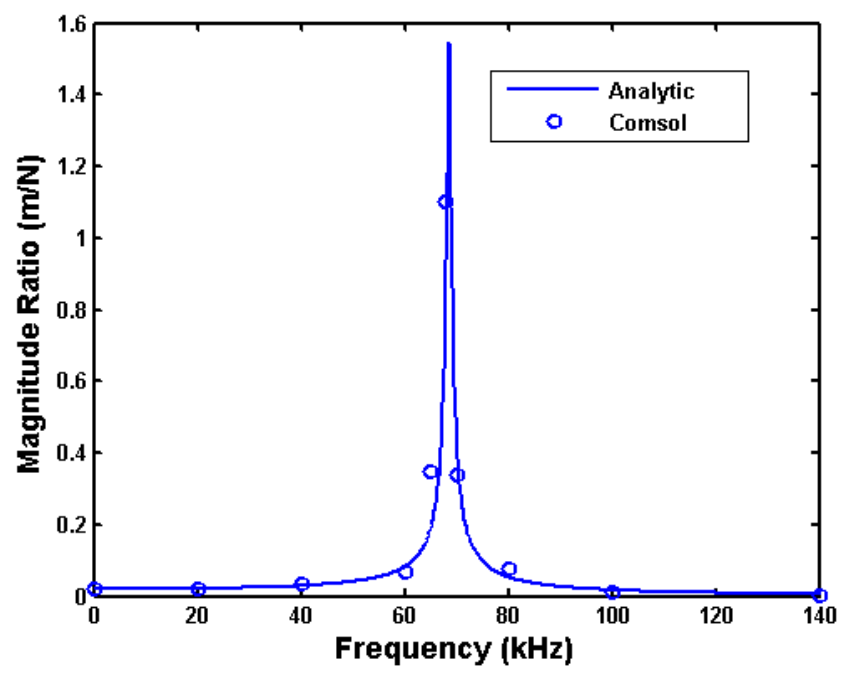

Figure 8. Comparison of analytical and numerical frequency responses for square plate with no hole, at ambient pressure of $300 \mathrm{~Pa}$, with folded leg stiffness of $0.5165 \mathrm{~N} / \mathrm{m}$.

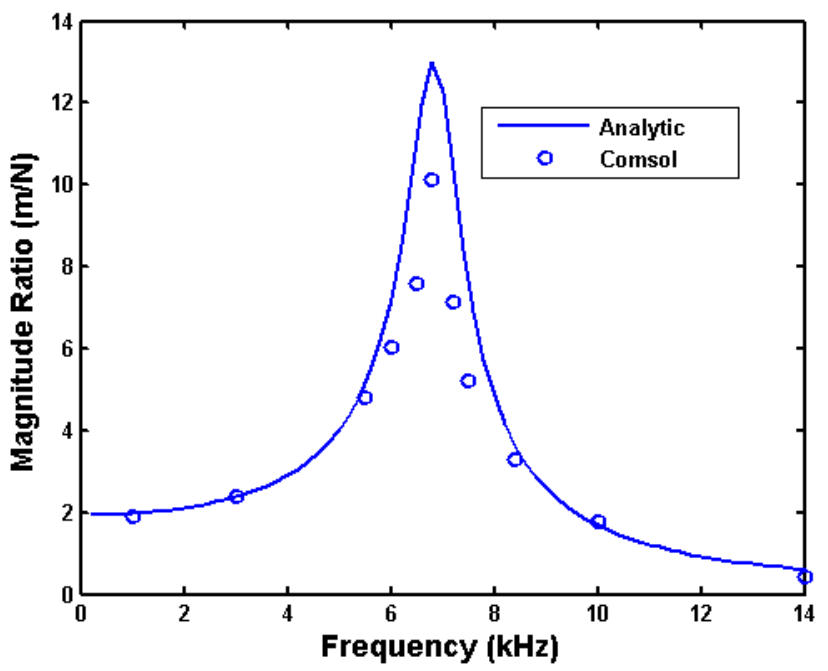

Figure 9 shows the finite element simulation of the pressure distribution underneath the closed and perforated plate in the equilibrium position during vibration. The ambient pressure is $300 \mathrm{~Pa}$ and the amplitude of vibration is $0.2 \mu \mathrm{m}$ in the $4 \mu \mathrm{m}$ gap at $67 \mathrm{KHz}$. The pressure around the edge of the plate and the hole is close to zero. The largest pressure is $3.2 \mathrm{~Pa}$ which appears in the corner regions. 
Figure 9. Distribution of pressure by damping.

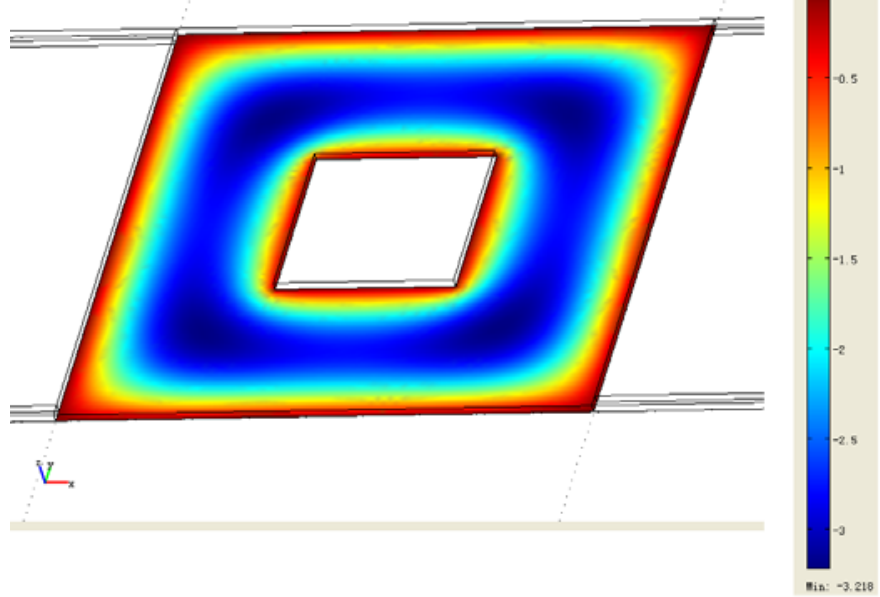

\section{Design Optimization Objective Function}

In a sensor application, the flat plate is covered by a polymer sensing layer as shown in Figure 10. The small golden balls represent chemical vapor molecules that have bound to the polymer and added mass to the plate. Our goal was to find the optimum hole size that would balance the need for large plate area for sensing and electrostatic actuation against large hole area for low air damping and high resonator $Q$.

Figure 10. Flat plate sensor structure.

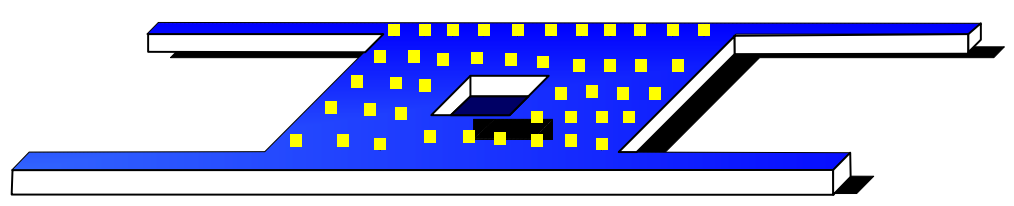

As a case study, we considered the absorption of a nerve gas analog (DMMP) onto a $\mathrm{PPESO} \mathrm{Na}^{+}$ polymer coating [15]. We estimated that a $100 \mathrm{~nm}$ thick polymer layer could absorb between $3.1 \mathrm{mg} / \mathrm{m}^{2}$ and $8.1 \mathrm{mg} / \mathrm{m}^{2}$. To be conservative, we considered the addition of $0.056 \mathrm{mg} / \mathrm{m}^{2}$ of DMMP to the entire plate area. For a $200 \mu \mathrm{m} \times 200 \mu \mathrm{m}$ plate with $67 \mu \mathrm{m} \times 67 \mu \mathrm{m}$ hole, the total added mass would be $2 \times 10^{-10} \mathrm{~g}$. We then calculated the effect of the absorbed mass on the resonant peak of the sensor structure for three different ambient pressure conditions. Table 2 shows the change in frequency and amplitude of the resonant peak. Large changes in both characteristics are desirable for a sensitive sensor. 
Table 2. Effect of the addition of nerve gas analog on resonant frequency and peak height when $2 \times 10^{-12} \mathrm{~g}$ mass is added to a $200 \mu \mathrm{m} \times 200 \mu \mathrm{m} \times 3 \mu \mathrm{m}$ silicon plate with $67 \mu \mathrm{m} \times 67 \mu \mathrm{m}$ hole, with leg stiffness of $5.16 \mathrm{~N} / \mathrm{m}$, and $3 \mu \mathrm{m}$ gap between plate and substrate.

\begin{tabular}{lllcc}
\hline & $\begin{array}{l}\text { Nominal Resonant } \\
\text { Frequency }\end{array}$ & $\begin{array}{l}\text { Change in Resonant } \\
\text { Frequency }\end{array}$ & $\begin{array}{l}\text { Nominal Peak } \\
\text { Magnitude Ratio }\end{array}$ & $\begin{array}{l}\text { Change in Peak } \\
\text { Magnitude Ratio }\end{array}$ \\
\hline $3 \mathrm{~Pa}$ & $22.88 \mathrm{kHz}$ & $-14 \mathrm{~Hz}$ & $287.5 \mathrm{~m} / \mathrm{N}$ & $-26.3 \mathrm{~m} / \mathrm{N}$ \\
$300 \mathrm{~Pa}$ & 25.92 & -16 & 1.622 & -0.005 \\
$3,000 \mathrm{~Pa}$ & 39.92 & -33 & 0.07753 & -0.00014 \\
\hline
\end{tabular}

In addition to ambient pressure, the effect of hole size was investigated. For these trials, we determined the frequency responses before and after adding $10 \%$ to the mass of the plate. The $10 \%$ mass change means the absolute changes in mass are different for each plate because the plate areas differ. Figure 11 compares the change in frequency response for three hole sizes in a $200 \mu \mathrm{m} \times 200 \mu \mathrm{m}$ plate. In all three cases, the peak amplitude drops and shifts to a slightly lower frequency when mass is added. The resonant frequency for the $160 \mu \mathrm{m} \times 160 \mu \mathrm{m}$ hole plate is much higher than the others because the large hole has eliminated most of the plate's mass.

Figure 11. Effect of a $10 \%$ mass increase on the frequency response of three plates.

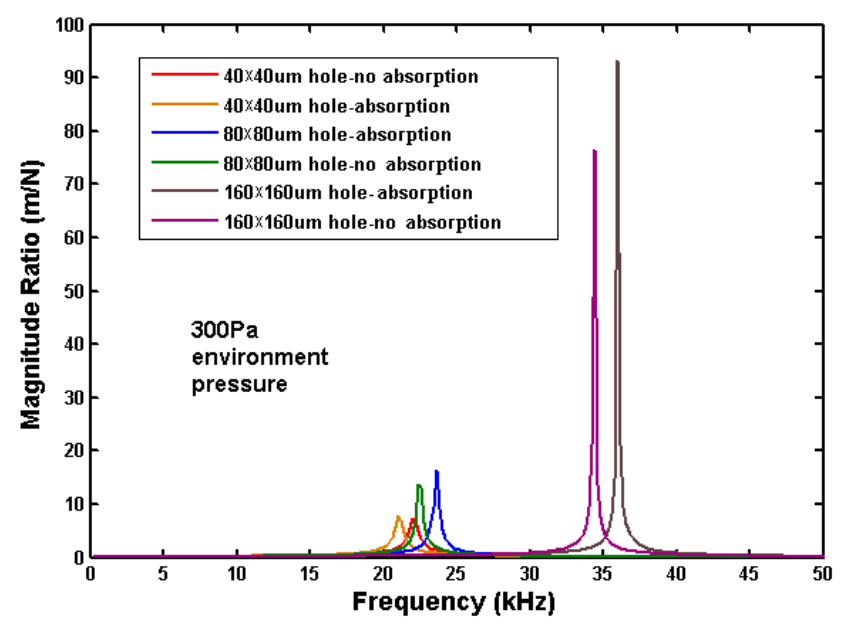

The design optimization process requires a meaningful measure of the change in frequency response. One measure is RMS, defined as:

$$
R M S=\sqrt{\frac{\sum_{i=1}^{n}\left(a_{1 i}-a_{2 i}\right)^{2}}{n}}
$$

Here $a_{1 \mathrm{i}}$ means the amplitude under the $i_{\text {th }}$ frequency step in the frequency response curve with no absorption and $a_{2 \mathrm{i}}$ means the amplitude under the $i_{\text {th }}$ frequency step in the frequency response curve with absorption. One difficulty with RMS is that it depends on the frequency range over which it is calculated. To simplify the calculation and remove the need to choose a frequency range, we propose a new measure $Q_{\mathrm{s}}$ : 


$$
Q_{S}=\sqrt{\frac{\left(S_{11}-S_{12}\right)^{2}+\left(S_{h 1}-S_{h 2}\right)^{2}}{2}}
$$

where $S_{11}, S_{12}, S_{\mathrm{h} 1}$, and $S_{\mathrm{h} 2}$ are as defined in Figure $12 . Q_{\mathrm{s}}$ is essentially a two point RMS, making use of the two resonant frequencies with and without absorption.

Figure 12. Illustration of the definition of $Q_{\mathrm{s}}$.

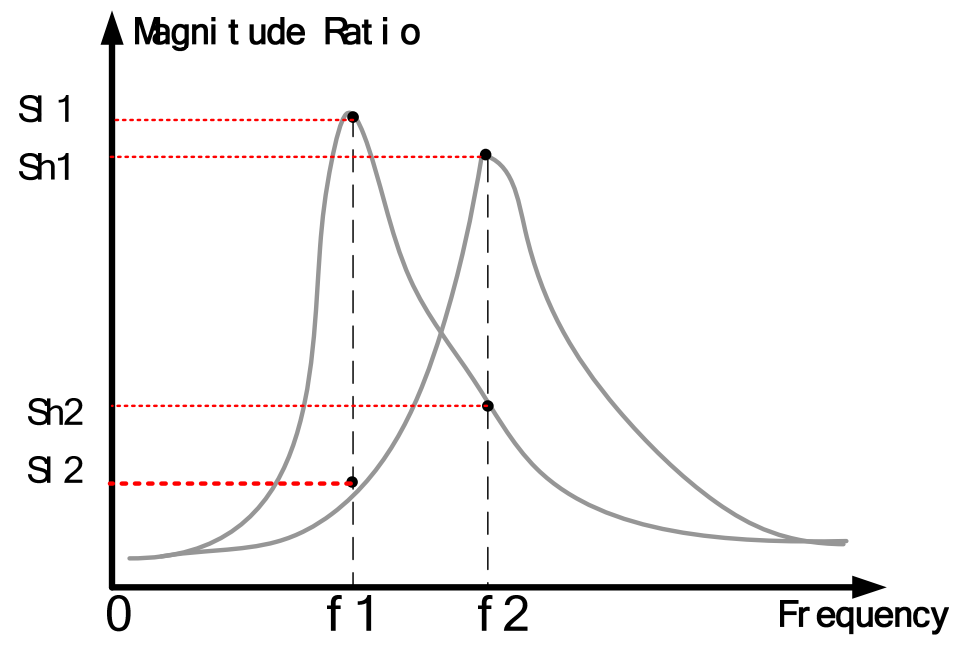

We compared the values of RMS and $Q_{\mathrm{s}}$ for hypothetical systems having a transfer function of the form:

$$
\frac{d x}{d F}=\frac{1}{m s^{2}+b s+k}
$$

The original mass is $m_{0}$, and the mass after chemical absorption is $m_{0}+\Delta m$. As an example, Figure 13 compares the frequency responses for a system before and after a $10 \%$ change in mass. The system parameters are: $m_{\mathrm{o}}=6 \times 10^{-11} \mathrm{~kg}, \Delta m=0.1 m_{\mathrm{o}}, b=1 \times 10^{-6} \mathrm{~N}-\mathrm{s} / \mathrm{m}$, and $k=50 \mathrm{~N} / \mathrm{m}$. The resonant peak drops from $145.3 \mathrm{kHz}$ to $138.5 \mathrm{kHz}$ with the extra mass.

Figure 13. Effect of $10 \%$ mass change on frequency response.

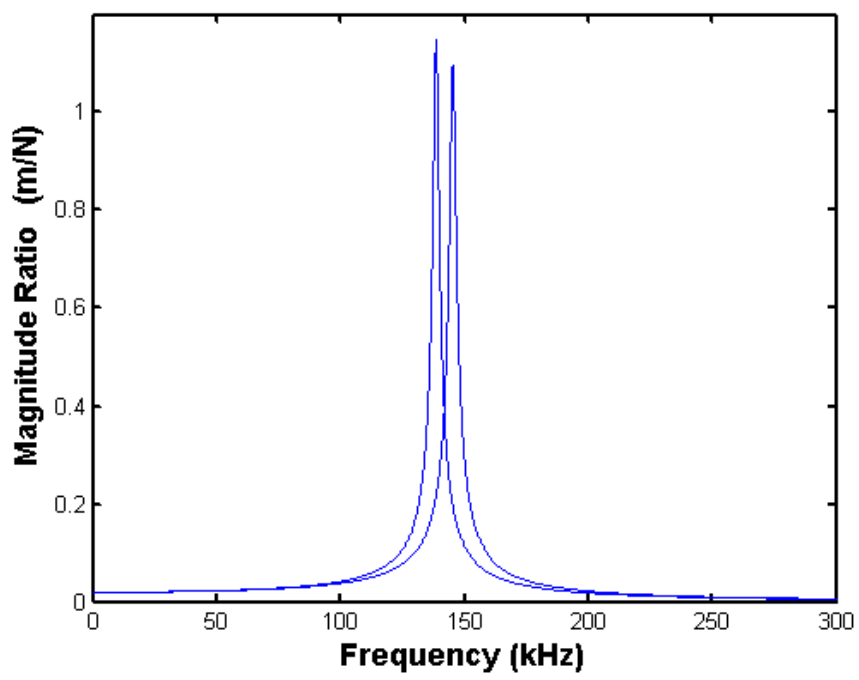


Figure 14 compares the RMS and $Q_{\mathrm{s}}$ values as a function of the percent mass change. The RMS was calculated using a frequency range of $0 \mathrm{~Hz}$ to $400 \mathrm{kHz}$ with a frequency step of $100 \mathrm{~Hz}$.

Figure 14. Comparison of $Q_{\mathrm{s}}$ and RMS as a function of mass change.

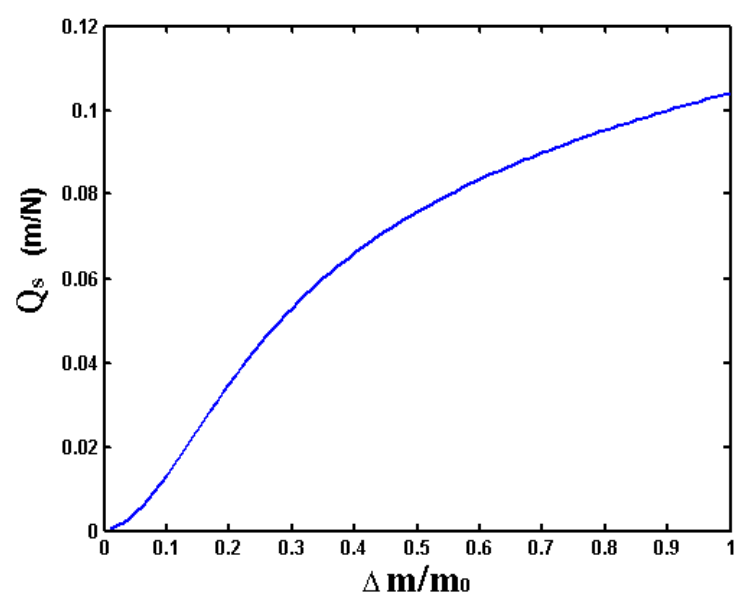

(a)

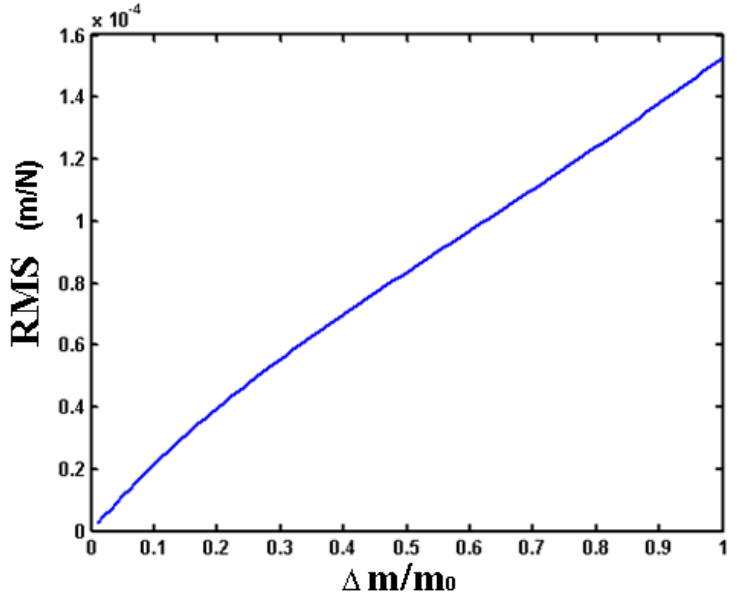

(b)

When the mass increases from zero to twice its original value, both the $Q_{\mathrm{s}}$ and the RMS increase monotonically, with RMS increasing more linearly than $Q_{\mathrm{s}}$. Next, we looked at how $Q_{\mathrm{s}}$ and RMS change with damping coefficient. In Figure 15, the RMS results are calculated using a 0 to $400 \mathrm{kHz}$ frequency range and with a $100 \mathrm{~Hz}$ frequency step in (a) and a $10 \mathrm{~Hz}$ frequency step in (b). The smaller frequency step produces a result that looks similar to the $Q_{\mathrm{s}}$ result. All three measures decrease as damping increases, reinforcing the importance of a sensor with high $Q$ (or low damping).

Figure 15. Comparison of RMS and $Q_{\mathrm{s}}$ for different damping coefficients.

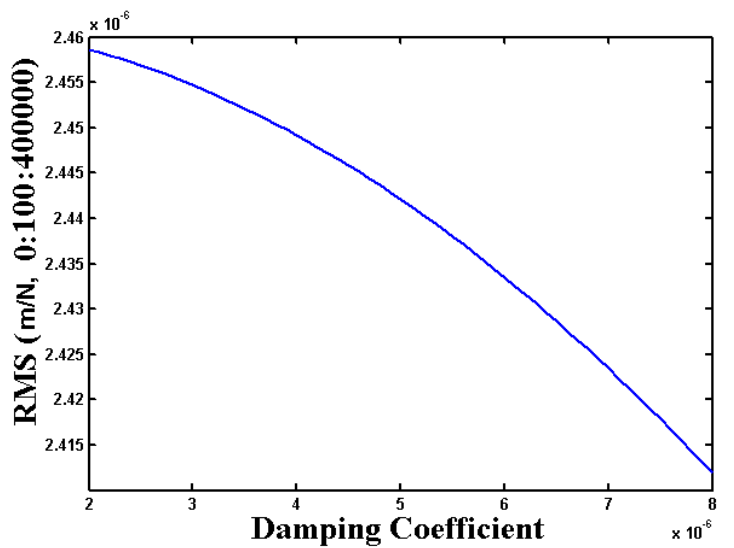

(a)

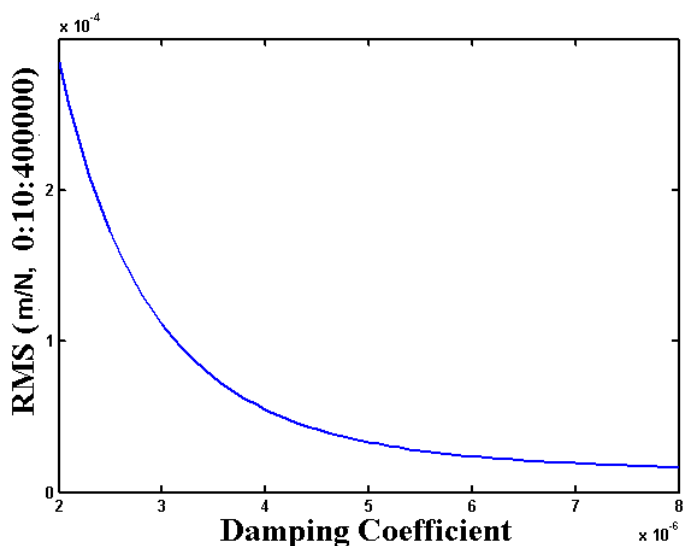

(b) 
Figure 15. Cont.

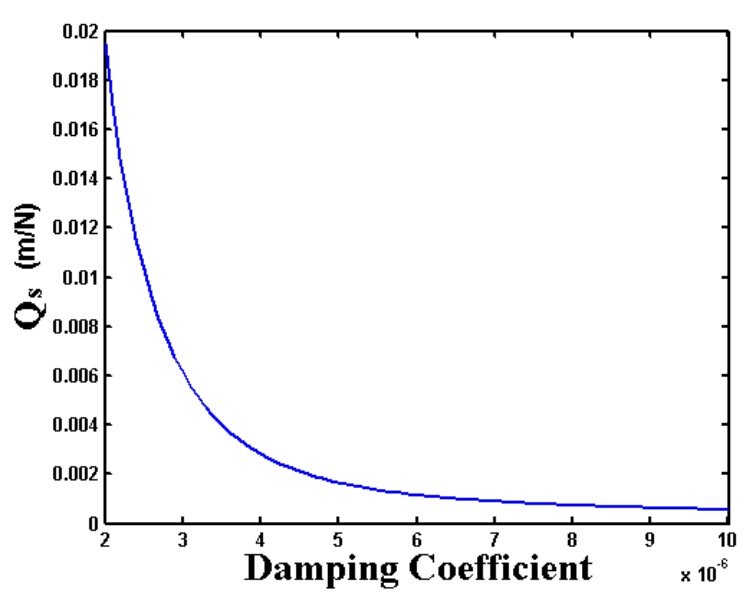

(c)

The parameter $Q_{\mathrm{s}}$ will now be used to determine an optimum hole size for a flat plate resonator. Consider the system shown in Figure 16. It is a flat plate connected to the substrate with four springs at its corners. The sensing electrode is shown as one of the two black electrodes underneath the suspension plate, and the actuation electrode is shown as another electrode. There is a hole in the middle of suspension plate. In our optimization problem we will use half of the plate's area as the sensing electrode, and half as the actuation electrode.

Figure 16. Schematic of square plate oscillator showing actuation and sensing electrodes.

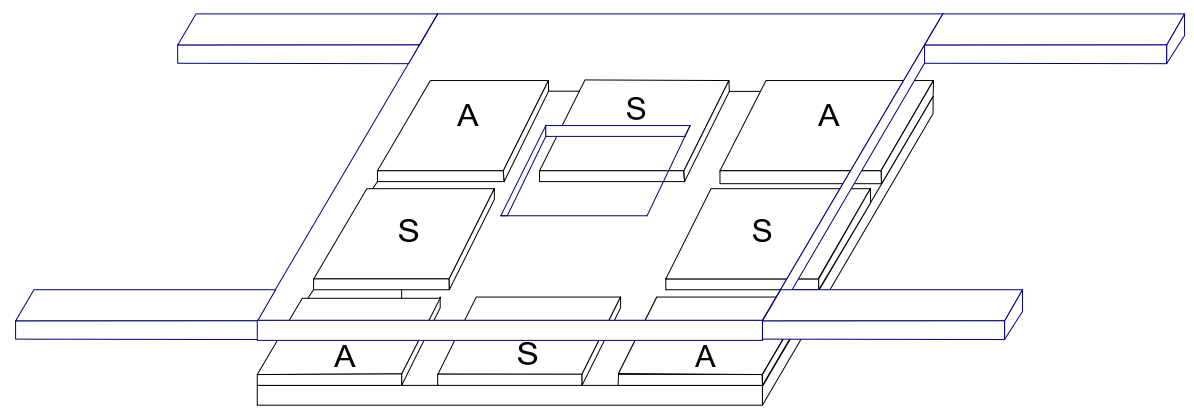

In the frequency responses discussed thus far, the magnitude ratio is calculated by dividing a displacement output by a force input $x / F$. However, the input to the actual device is a voltage, and the output of the actual device is capacitance. The magnitude ratio is thus $\Delta C / \Delta V$. We further simplify the optimization problem by considering small vibrations about an offset displacement. In this way we linearize the voltage-to-electrostatic force and capacitance-to-displacement relationships. For this problem, the magnitude ratio of interest is $\Delta C / \Delta V$. This new magnitude ratio can be found from:

$$
\frac{d C}{d V}=\frac{d x}{d F} \frac{d C}{d x} \frac{d F}{d V}
$$

For the rigid plate attached to the substrate with folded leg springs:

$$
\frac{d x}{d F}=\frac{1}{m s^{2}+b s+k}
$$


where $b$ and $k$ incorporate the effects of squeeze film damping (Equations 1-6). The system will be oscillated with small amplitudes around a setpoint with displacement $x_{0}$ (measured as capacitance $C_{0}$ ) at a force $F_{0}$ (realized by applying the voltage $V_{0}$ ). The equation for capacitance is:

$$
C=\frac{\varepsilon A_{s}}{g_{o}-x}
$$

Differentiating the $\mathrm{C}$ equation:

$$
\frac{d C}{d x}=\frac{\varepsilon A_{s}}{\left(g_{o}-x_{o}\right)^{2}}
$$

The actuation force is:

$$
F=\frac{\varepsilon A_{a} V^{2}}{2\left(g_{o}-x_{o}\right)^{2}}=k x
$$

where $A_{\mathrm{a}}$ is the actuating area, $V$ is the applied voltage, and $k$ is the stiffness of the corner springs. The displacement $x$, depends on $V$ but also on $k$. To obtain an expression for $\mathrm{d} F / \mathrm{d} V$ that doesn't have $x$ in it, we substitute $x=F / k$ in Equation (17). After rearranging, we obtain:

$$
\frac{1}{k^{2}} F^{3}-\frac{2 g_{o}}{k} F^{2}+g_{o}^{2} F-\frac{\varepsilon A_{a} V^{2}}{2}=0
$$

Differentiating this equation gives:

$$
\frac{3 F^{2}}{k^{2}} d F-\frac{4 g_{o} F}{k} d F+g_{o}^{2} d F-\varepsilon A_{a} V d V=0
$$

Solving for $\mathrm{d} F / \mathrm{d} V$ yields:

$$
\frac{d F}{d V}=\frac{\varepsilon A_{a} V_{o}}{\left(3 \frac{F^{2}}{k^{2}}-4 g_{o} \frac{F}{k}+g_{o}^{2}\right)}
$$

The displacement $\mathrm{x}$ can be substituted for $F / k$. At the setpoint of $V_{\mathrm{o}}$ and $F_{\mathrm{o}}$, the slope is:

$$
\frac{d F}{d V}=\frac{\varepsilon A_{a} V_{o}}{\left(g_{o}-x_{o}\right)\left(g_{o}-3 x_{o}\right)}
$$

Combining the factors in Equations (14), (16), and (21) yields:

$$
\frac{d C}{d V}=\frac{\varepsilon^{2} A_{s} A_{a} V_{o}}{\left(g_{o}-x_{o}\right)^{3}\left(g_{o}-3 x_{o}\right)} \frac{1}{m s^{2}+b s+k}
$$

Figure 17 shows the frequency responses of a system using two different types of magnitude ratios. The system consists of a $200 \mu \mathrm{m} \times 200 \mu \mathrm{m} \times 3 \mu \mathrm{m}$ plate with $4 \mu \mathrm{m}$ gap and supported by four folded beams with the stiffness of $51.65 \mathrm{~N} / \mathrm{m}$. The hole is centered in the middle of the plate. Half of the plate area is used for actuation and the other half for capacitive sensing. The surrounding air pressure is $101,000 \mathrm{~Pa}$, and the mass change due to absorbed vapor will be $10 \%$. The setpoint voltage $V_{\mathrm{o}}$ is $10 \mathrm{~V}$. The magnitude ratio in the first plot is in the form of displacement over force, and the ratio in the second plot is capacitance change over input voltage change. Note that the second plot of $\mathrm{d} C / \mathrm{d} V$ differs from the first one of $\mathrm{d} x / \mathrm{d} F$ only by a constant. As shown in Equation (22), that constant depends on the areas available for sensing and actuation. 
Figure 17. Effect of hole size on sensor sensitivity (defined as $Q_{\mathrm{s}}$ ) for $200 \mu \mathrm{m} \times 200 \mu \mathrm{m} \times$ $3 \mu \mathrm{m}$ plate, with $g_{\mathrm{o}}=4 \mu \mathrm{m}, V_{\mathrm{o}}=10 \mathrm{~V}, P_{\mathrm{a}}=101,000 \mathrm{~Pa}, k_{\mathrm{flex}}=51.65 \mathrm{~N} / \mathrm{m}, \Delta m / m_{\mathrm{o}}=0.1$.
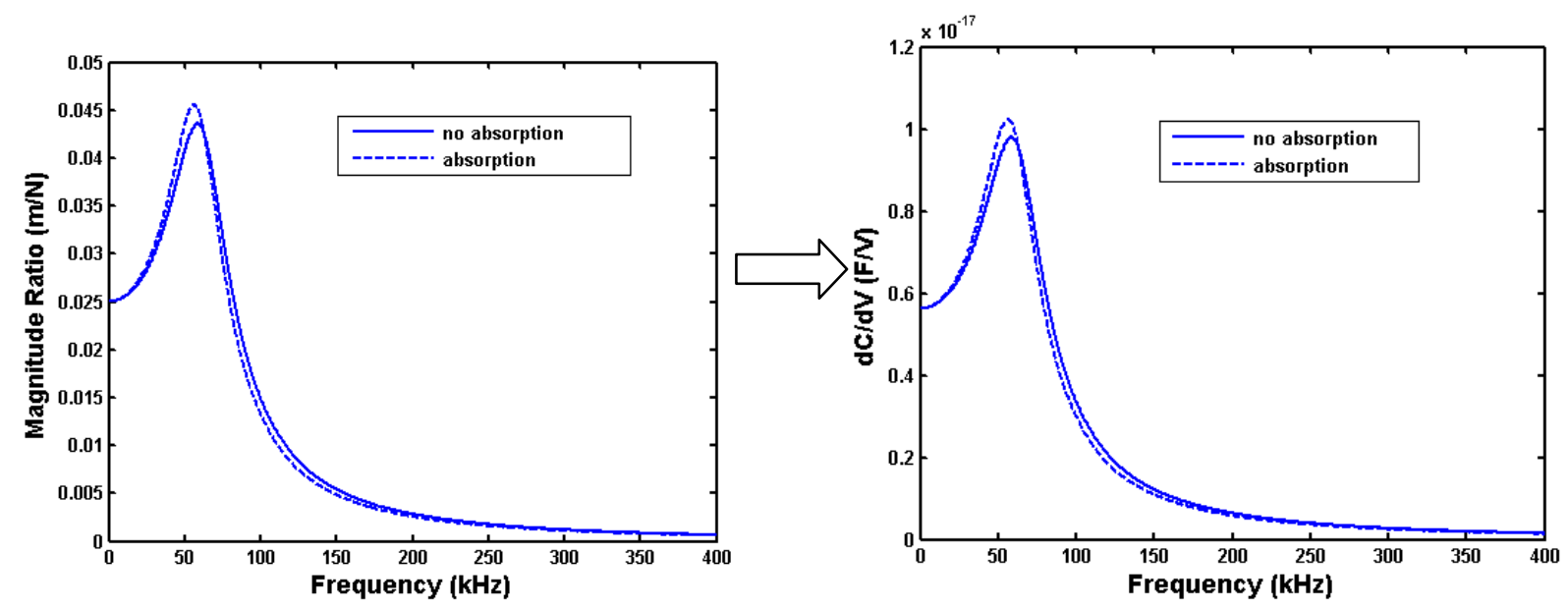

\section{Determining Optimal Hole Size}

The pieces are now in place to look at an optimal design. The goal is to maximize $Q_{\mathrm{s}}$ as calculated from frequency responses that use $\mathrm{d} C / \mathrm{d} V$ as the magnitude ratio. The square plate is assumed to be $200 \mu \mathrm{m} \times 200 \mu \mathrm{m} \times 3 \mu \mathrm{m}$ with $4 \mu \mathrm{m}$ gap. The stiffness of structure is $51.65 \mathrm{~N} / \mathrm{m}$ and the setpoint voltage $V_{\mathrm{o}}$ is $10 \mathrm{~V}$. The surrounding air pressure is $101,000 \mathrm{~Pa}$, and the mass change due to absorbed vapor will be $10 \%$. We wish to find the hole size that maximizes sensor sensitivity. Figure 18 shows how $Q_{\mathrm{s}}$ changes with hole size. The units for $Q_{\mathrm{s}}$ are farads/volt. Note that the highest $Q_{\mathrm{s}}$ occurs for a hole size of about $149 \mu \mathrm{m}$. In other words, this is the hole size that will yield the best sensitivity for this particular plate size, gap, setpoint voltage, and ambient air pressure.

Figure 18. Effect of hole size on sensor sensitivity (defined as $Q_{\mathrm{s}}$ ) for $200 \mu \mathrm{m} \times 200 \mu \mathrm{m} \times$ $3 \mu \mathrm{m}$ plate, with $g_{\mathrm{o}}=4 \mu \mathrm{m}, V_{\mathrm{o}}=10 \mathrm{~V}, P_{\mathrm{a}}=101,000 \mathrm{~Pa}, k_{\mathrm{flex}}=51.65 \mathrm{~N} / \mathrm{m}, \Delta m / m_{\mathrm{o}}=0.1$.

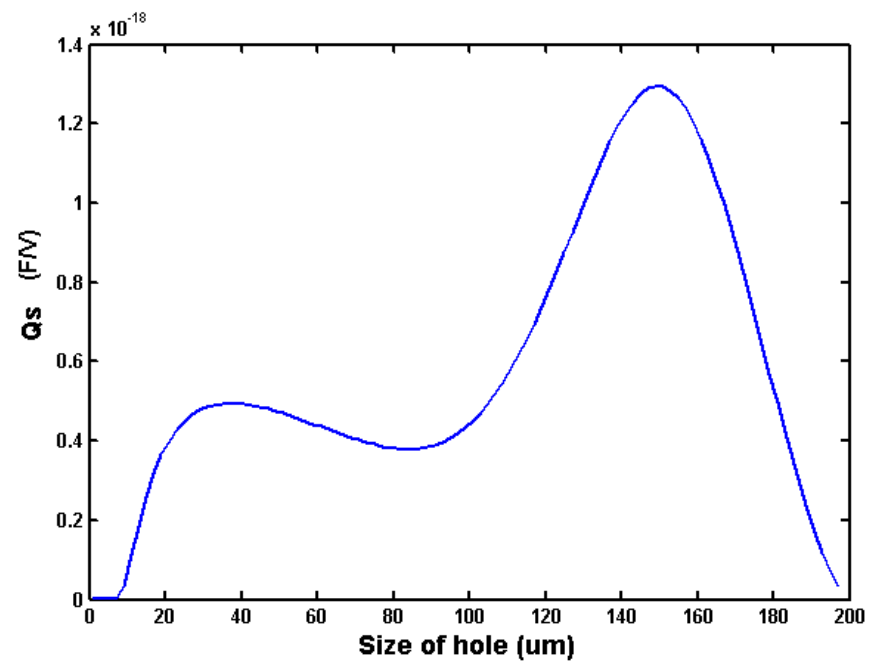

Given a particular hole size, there is also an optimum gap. Figure 19 shows how $Q_{\text {s }}$ changes with gap when the hole size is fixed at $149 \mu \mathrm{m} \times 149 \mu \mathrm{m}$. A large gap will have a favorable effect on a 
resonator's $Q$. However, the amplitude of motion will fall off as the gap increases, thus explaining why $Q_{\mathrm{s}}$ decreases for a gap above about $4.8 \mu \mathrm{m}$ in Figure 19.

Figure 19. Effect of gap on sensor sensitivity for $200 \mu \mathrm{m} \times 200 \mu \mathrm{m} \times 3 \mu \mathrm{m}$ plate, with $V_{\mathrm{o}}=10 \mathrm{~V}, P_{\mathrm{a}}=101,000 \mathrm{~Pa}, k_{\mathrm{flex}}=51.65 \mathrm{~N} / \mathrm{m}, \Delta \mathrm{m} / \mathrm{m}_{\mathrm{o}}=0.1$, hole size of $149 \mu \mathrm{m} \times 149 \mu \mathrm{m}$.

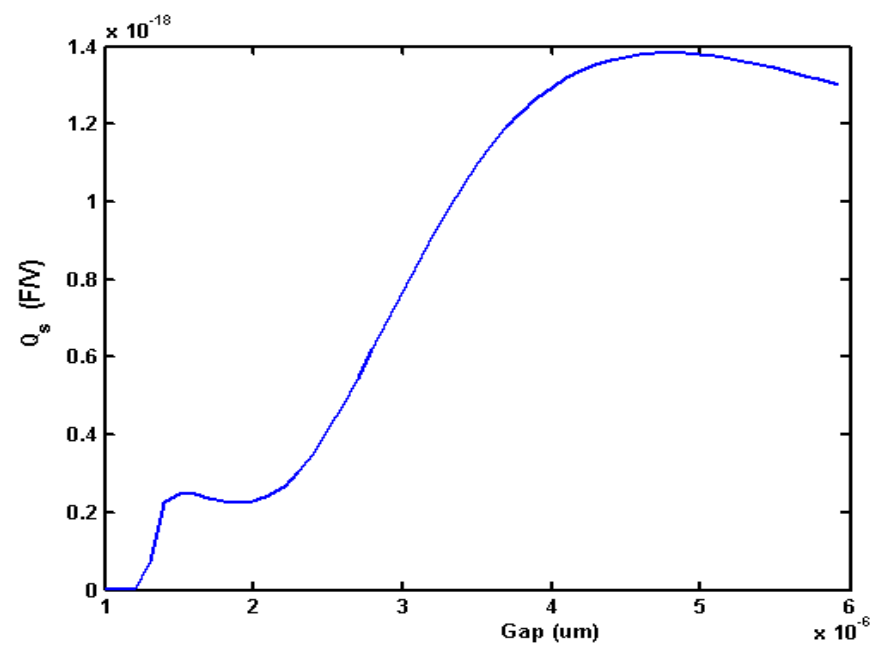

In the examples above, the electrode area was split evenly between actuation area and capacitive sensing area. We checked to see if there was a more favorable split. We calculated $Q_{\mathrm{s}}$ while varying the ratio of actuation area to the total plate area from 5\% to $95 \%$. Figure 20 shows that the maximum value occurs at 50\% (where the areas are evenly split). After looking at Equation (22), this result makes sense. The amplitude in the frequency response depends on the product of $A_{\mathrm{a}}$ and $A_{\mathrm{s}}$. Given that the sum of $A_{\mathrm{a}}$ and $A_{\mathrm{s}}$ is fixed, the maximum product occurs when $A_{\mathrm{a}}$ and $A_{\mathrm{s}}$ are equal.

Figure 20. Effect of the actuation area on sensitivity for $200 \mu \mathrm{m} \times 200 \mu \mathrm{m} \times 3 \mu \mathrm{m}$ plate, with $V_{\mathrm{o}}=10 \mathrm{~V}, g_{\mathrm{o}}=4 \mu \mathrm{m}, P_{\mathrm{a}}=101,000 \mathrm{~Pa}, k_{\mathrm{flex}}=51.65 \mathrm{~N} / \mathrm{m}, \Delta m / m_{\mathrm{o}}=0.1$, hole size of $149 \mu \mathrm{m} \times 149 \mu \mathrm{m}$.

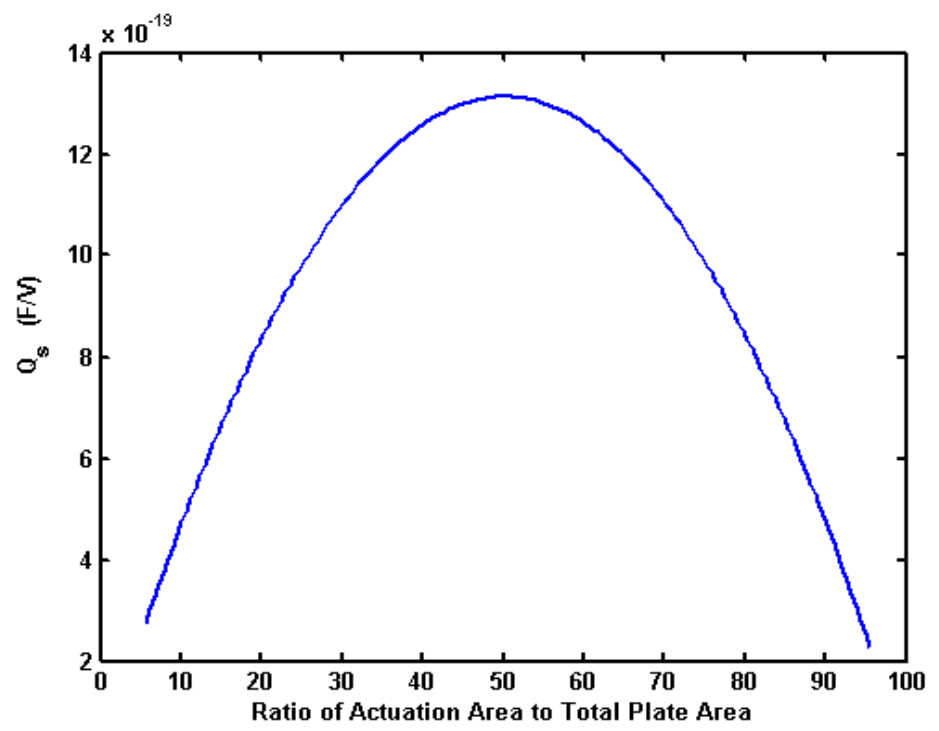


Finally, we looked at finding the optimum combination of hole size and gap. Figure 21 plots $Q_{\mathrm{s}}$ versus both hole size and gap for the $200 \mu \mathrm{m} \times 200 \mu \mathrm{m} \times 3 \mu \mathrm{m}$ plate. The peak value of $Q_{\mathrm{s}}\left(1.81 \times 10^{-18}\right.$ farads/volt) occurs when the gap is $5.2 \mu \mathrm{m}$ and the hole size is $144 \mu \mathrm{m} \times 144 \mu \mathrm{m}$.

Figure 21. Effect of the hole size and gap on sensitivity for $200 \mu \mathrm{m} \times 200 \mu \mathrm{m} \times 3 \mu \mathrm{m}$ plate, with $V_{\mathrm{o}}=10 \mathrm{~V}, P_{\mathrm{a}}=101,000 \mathrm{~Pa}, k_{\mathrm{flex}}=51.65 \mathrm{~N} / \mathrm{m}, \Delta m / m_{\mathrm{o}}=0.1$.

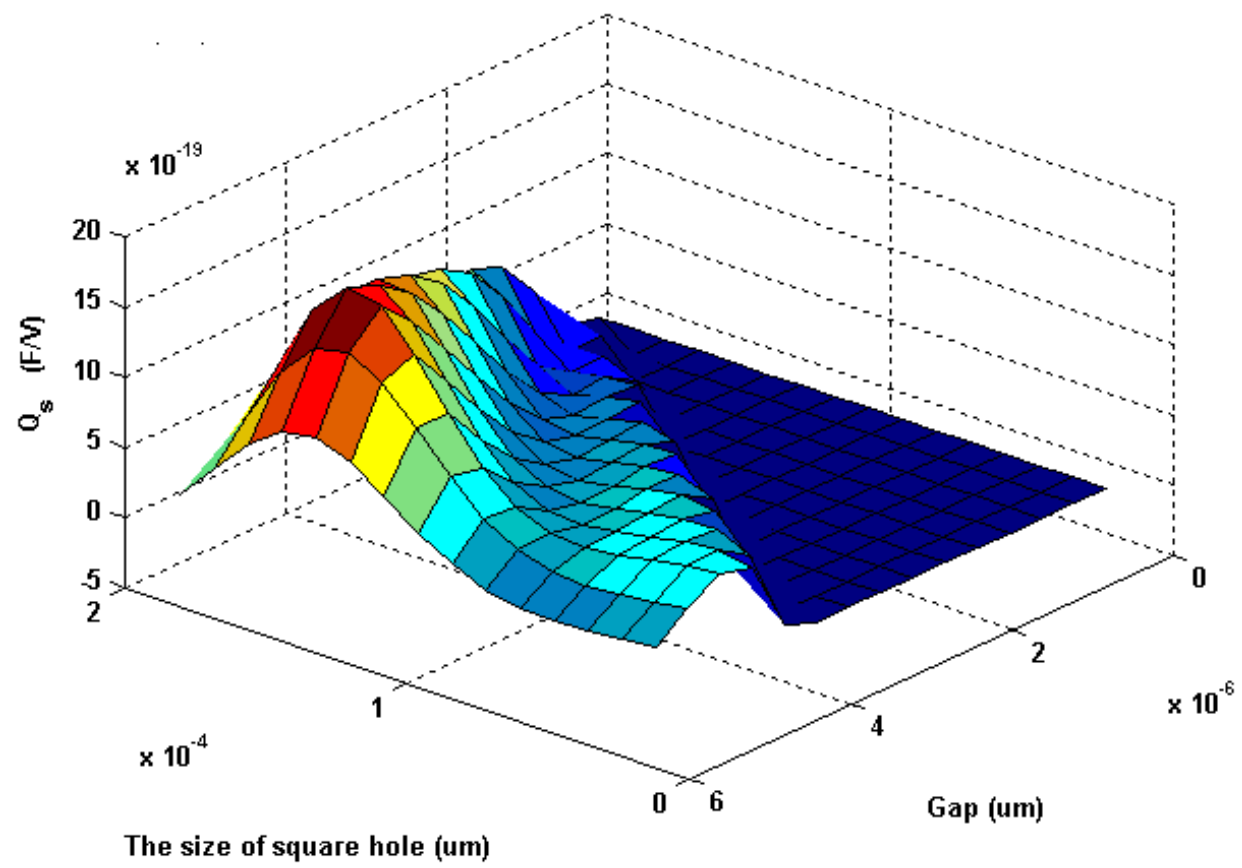

\section{Conclusions}

In summary, we have adopted an analytical squeeze film damping model that adequately replicates finite element modeling results over a wide range of conditions. In addition, we have defined an objective function that permits the calculation of an optimal design (given particular constraints) that takes into account electrostatic actuation, capacitive sensing, and squeeze film damping. Results for optimum hole size, gap, and electrode area partitioning have been presented. Future work involves investigating additional factors (such as setpoint voltage, ambient pressure, and expected mass change) as well as additional geometries (such as non-square plates, multiple holes, and bending cantilevers).

\section{Acknowledgements}

This work was supported in part by the State of Michigan 21st Century Jobs Fund project number 06-1-P1-0283.

\section{References and Notes}

1. Ziegler, C. Cantilever-based biosensors. Anal. Bioanal. Chem. 2004, 379, 946-959.

2. Goeders, K.M.; Bottomley, L.A. Microcantilevers: Sensing chemical interactions via mechanical motion. Chem. Rev. 2008, 108, 522-542. 
3. Bao, M.; Yang, H. Squeeze film air damping in MEMS. Sens. Actuat. A 2007, 136, 3-27.

4. Starr, J.B. Squeeze film damping in solid state accelerometer. In Proceedings of Technical Digest, IEEE Solid State Sensor and Actuator Workshop, Hilton Head Island, SC, USA, June 1990; pp. 44-47.

5. Sadd, M.H.; Stiffler, A.K. Squeeze film damper: Amplitude effects at low squeeze numbers. $J$. Eng. Indust. 1975, 97, 1366-1370.

6. Blech, J. On isothermal squeeze films. J. Lubric. Technol. 1983, 105, 615-620.

7. Andrews, M.; Harris, I.; Turner, G. A comparison of squeeze-film theory with measurements on a microstructure. Sens. Actuat. 1993, A36, 79-87.

8. Veijola, T.; Kuisma, R.H.; Lahdenpera, J. Circuit simulation model of gas damping in microstructures with nontrivial geometries. In Proceedings of Transducers '95 and Eurosensors IX, Stockholm, Sweden, June 1995; pp. 36-39.

9. Yang, Y.J.; Gretillat, S.D. Numerical simulation of compressible squeezed-film damping. In Proceedings of Technical Digest Solid-State Sensors and Actuator Workshop, Hilton Head Island, SC, USA, June 1996; pp. 76-79.

10. Yang, Y.J.; Gretillat, M.A.; Senturia, S.D. Effect of air damping on the dynamics of nonuniform deformations of microstructures. Digest of Technical Papers, In Proceedings of International Conference on Solid-State Sensors and Actuators (Transducers '97), Chicago, IL, USA, June 1997; pp. 1093-1096.

11. Kim, E.S.; Cho, Y.H.; Kim, M.U. Effect of holes and edges on the squeeze film damping of perforated micromechanical structures. In MEMS'99, Orlando, FL, USA, January 1999; pp. 296-301.

12. Homentcovschi, D.; Miles, R.N. Modeling of viscous damping of perforated planar microstructures: Applications in acoustics. J. Acoust. Soc. Am. 2004, 116, 2939-2947.

13. Bao, M.; Yang, H.; Sun, Y.; French, P.J. Modified Reynolds' equation and analytical analysis of squeeze-film air damping of perforated structures. J. Micromech. Microeng. 2003, 13, 795-800.

14. Darling, R.B.; Hivick, C.; Xu, J. Compact analytical modeling of squeeze film damping with arbitrary venting conditions using a Green's function approach. Sens. Actuat. 1998, A70, 32-41.

15. Yue, H.; Wu, M.; Xue, C.; Velayudham, S.; Waldeck, D.H. Evolution in the Supramolecular Complexes between Poly(phenylene ethynylene)-Based Polyelectrolytes and Octadecyltrimethylammonium Bromide as Revealed by Fluorescence Correlation Spectroscopy. J. Phys. Chem. B 2008, 112, 8218-8226.

(C) 2010 by the authors; licensee MDPI, Basel, Switzerland. This article is an open access article distributed under the terms and conditions of the Creative Commons Attribution license (http://creativecommons.org/licenses/by/3.0/). 